\title{
A Combination Method of Improved Grey Relational Degree and AHP for Effectiveness Evaluation
}

\author{
HUANG Guo-qing 1, 2, a , ZHAO Wei-bin ${ }^{1, ~ b}$, XU Shi-hong ${ }^{2, c}$ \\ ${ }^{1}$ School of Information Engineering, Zhengzhou University, Zhengzhou 450001, China \\ ${ }^{2}$ Department of Aeronautic Electronic Engineering, the First Aeronautical College of Air Force, \\ Xinyang 464000, China \\ ahguoqing@163.com, bzzuweibin@163.com
}

\begin{abstract}
Keywords: Delphi method; AHP; Combination weighting approach; Gray relational degree; Effectiveness evaluation

Abstract. Aiming at the shortcoming that the calculation of the gray relational coefficient is influenced by the number of schemes and distinguishing coefficient, which causes inconsistency of the evaluation results in the traditional gray relational degree, an effectiveness evaluation method is proposed, which is based on the combination of the improved grey relational degree and the analytic hierarchy process (AHP). It uses Delphi method and AHP to establish the scientific and reasonable index system of complex systems; the combination weighting method that AHP combined with entropy method is used to determine the weights, weights can meet the subjective and objective view of demand, which makes the effectiveness evaluation results more reasonable; the compositor results are not affected by the number of schemes and distinguishing coefficient, which overcomes the shortcoming of the traditional grey relational degree. The model of the improved effectiveness evaluation method is established, and the concrete steps of the improved method are given. Three methods were used to analyze the example, the results show that the improved method is reasonable and feasible.
\end{abstract}

\section{Introduction}

The grey system theory is proposed by Professor Deng Julong. The theory is used to study the uncertainty problem of "partial information is known, part of information is unknown" ${ }^{[1]}$. Gray relational degree is an important part of grey system theory which is used for quantitative analysis of the degree of relationship between the system sequences ${ }^{[2]}$. In order to solve the problem of uncertain decision making, Professor Deng Julong put forward the classical grey relational degree. The grey relational comprehensive optimization method which considers both the optimal reference plan and the worst scheme make the evaluation result more reasonable ${ }^{[3]}$. Grey relational analysis is used to determine the judgment matrix in the ANP method, which overcomes the subjectivity and unreliability of the weights determined by expert scoring ${ }^{[4]}$. Five indexes which influence the low interception performance of radar are given, and the weight of the index is weighted according to the important degree of the index which improved the credibility of the evaluation results ${ }^{[5]}$. A single data link network effectiveness evaluation index system was established, and put forward grey analytic hierarchy process to evaluate the data chain networking scheme which improved the coordination ability of the combat personnel ${ }^{[6]}$. The combination of the Taguchi method and the gray relational analysis was used to optimize the properties of the 7075 aluminum alloy on the electric drill rig ${ }^{[7]}$ and so on.

However, the above methods calculate gray relational coefficient based on the Eq. 1 .

$$
\mathrm{r}\left(\mathrm{x}_{0}(\mathrm{k}), \mathrm{x}_{\mathrm{i}}(\mathrm{k})\right)=\frac{\min _{\mathrm{i}} \min _{\mathrm{k}}\left|\mathrm{x}_{0}(\mathrm{k})-\mathrm{x}_{\mathrm{i}}(\mathrm{k})\right|+\xi \max _{\mathrm{i}} \max _{\mathrm{k}}\left|\mathrm{x}_{0}(\mathrm{k})-\mathrm{x}_{\mathrm{i}}(\mathrm{k})\right|}{\left|\mathrm{x}_{0}(\mathrm{k})-\mathrm{x}_{\mathrm{i}}(\mathrm{k})\right|+\xi \max _{\mathrm{i}} \max _{\mathrm{k}}\left|\mathrm{x}_{0}(\mathrm{k})-\mathrm{x}_{\mathrm{i}}(\mathrm{k})\right|} \text {. }
$$

$\left|\mathrm{x}_{0}(\mathrm{k})-\mathrm{x}_{\mathrm{i}}(\mathrm{k})\right|$ represents the absolute difference between $\mathrm{x}_{0}(\mathrm{k})$ and $\mathrm{x}_{\mathrm{i}}(\mathrm{k})$ of the $\mathrm{K}$ point. $\max _{i} \max _{k}\left|x_{0}(k)-x_{i}(k)\right|$ indicates the maximum absolute difference, $\min _{i} \min _{k}\left|x_{0}(k)-x_{i}(k)\right|$ indicates the minimum absolute difference. a. Because the minimum absolute difference and the maximum absolute difference will be affected by the number of schemes, so the relational coefficient of each time point will 
change when the number of schemes changes, which will result in the change of evaluation results. $b$. Distinguishing coefficient $\xi$ determines the maximum absolute difference contribution of relational coefficients but the choice of $\xi$ will impact the orders of the schemes, the evaluation result is inconsistency ${ }^{[8,9]}$.

\section{Analysis of the model of improved efficiency evaluation method}

Whether the reasonable relational degree model can be used to quantize the geometric approach degree of sequences correctly relate to the success or failure of the grey relational analysis ${ }^{[10]}$. In order to solve the above problems, this paper puts forward the effectiveness evaluation method that AHP combined with improved grey relational degree. According to Delphi method and AHP to establish the scientific and reasonable index system and establish the hierarchical relationship, The bottom indicators are divided into vector module according to the relation of the criterion layer, and the weighted value of the index is used as a vector element, the grey relational coefficient calculation model is established based on Euclidean function, that is, through the Eq. 2, Eq. 3 to calculate the relational coefficient.

$$
\mathrm{d}(X, Y)=\sqrt{\sum_{\mathrm{i}=1}^{\mathrm{m}}\left(Y_{\mathrm{i}}-X_{\mathrm{i}}\right)^{2}} \text {. }
$$

$\mathrm{X}_{\mathrm{i}}, \mathrm{Y}_{\mathrm{i}}$ express vector, $\mathrm{d}(\mathrm{X}, \mathrm{Y})$ express the Euclidean distance and $\mathrm{d}(\mathrm{Y}, \mathrm{Z}) \geq 0$.

Calculate the correlation coefficient By Eq. 3.

$$
\mathrm{r}(X, Y)=\frac{\alpha}{\alpha+\mathrm{d}(X, Y)} \text {. }
$$

$\mathrm{r}(\mathrm{X}, \mathrm{Y})$ represents the relational coefficient between the vector $\mathrm{X}$ and the vector $\mathrm{Y}$, which satisfies normativity and proximity. $\alpha$ express distinguishing coefficient, $\alpha>0 . \alpha=0.05$ in this paper.

(1) normativity

Because $\alpha>0$ and $d(X, Y) \geq 0$ so $0<r(X, Y) \leq 1$, when $d(X, Y)=0, r(X, Y)=1 \Leftrightarrow X=Y$.

(2) proximity

Because the closer of vector $\mathrm{X}$ and $\mathrm{Y}$, the smaller $\mathrm{d}(\mathrm{X}, \mathrm{Y})$ is, the relational coefficient is inversely proportional to the Euclidean distance. The relational degree of vector $\mathrm{X}, \mathrm{Y}$ is bigger so $\mathrm{r}(\mathrm{X}, \mathrm{Y})$ is bigger.

The minimum absolute difference and the maximum absolute difference are not used to calculate relational coefficient in the improved method so the calculation of the relational degree is not affected by the number of schemes. The relational coefficient is inversely proportional to the Euclidean distance so distinguishing coefficient does not affect the consistency of the compositor results. The calculation of relational coefficient takes full account of the weight of each index, which not only meets the basic requirements of gray relational degree, but also can better reflect the relational degree between the comparison sequence and the reference sequence. The improved method overcomes the shortcomings of the traditional relational coefficient method that the evaluation results are inconsistency with the effect of the number of schemes and distinguishing coefficient.

In the process of effectiveness evaluation, the index weight represents the contribution of the underlying factor to the upper level, it occupies a very important position and has a great influence on the evaluation results. Therefore, whether it can establish a scientific and reasonable index weight related to the reliability of the results of evaluation. At present, the mature weighting methods have the subjective weighting method such as: analytic hierarchy process, DARE, expert investigation method and so on. The objective weighting methods have principal component analysis method, maximizing deviation method, entropy method ${ }^{[11]}$ and so on. The subjective weighting method and the objective weighting method have certain preference and complementarity, in order to make the results more reasonable and reliable, the improved method uses the combination weighting method to determine the weight of the index. It is not only considers the preference of decision makers on the index, but also tries to use the objective information contained in the observation data effectively. 


\section{The concrete steps of the improved method}

According to the improvement of the effectiveness evaluation method, the process dealing with complex large systems of the improved method is as follows:

Step one set up the index system

Delphi method uses the knowledge and experience of experts through exchange of information for many times and inductive synthesis, it can give the index of complex system reasonably. When the index system is established, the complex problem is usually decomposed into some easily measurable indicators. The process of determining index system by using Delphi method is shown in Figure 1.

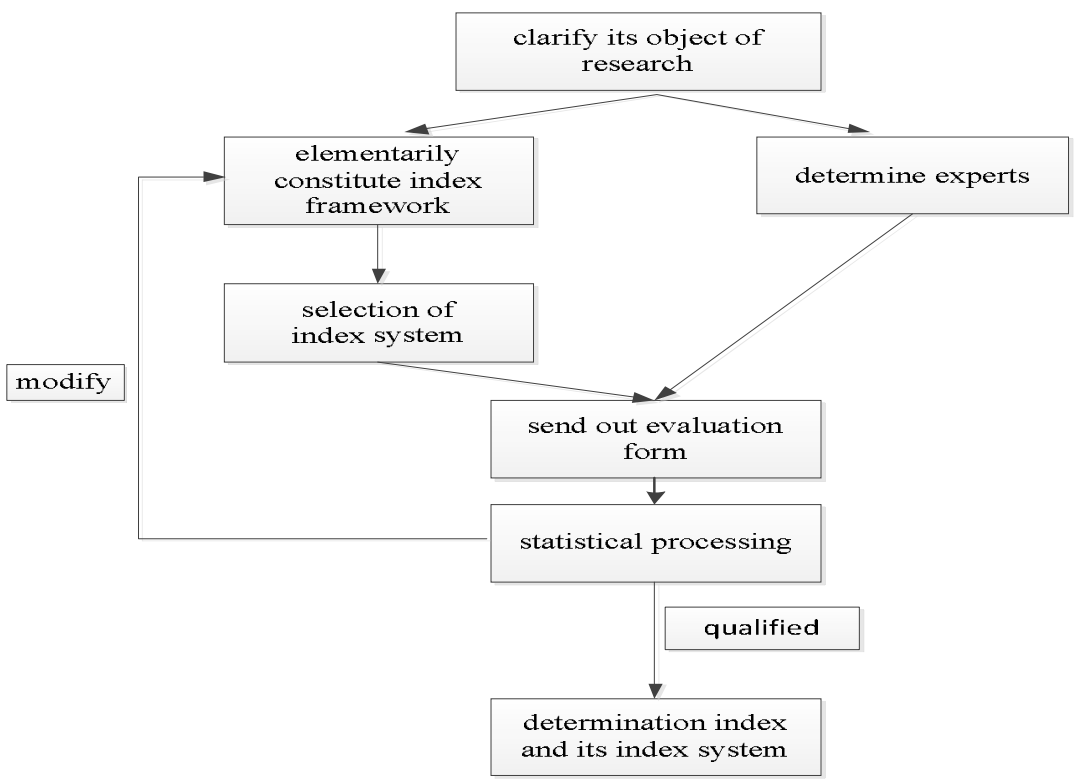

Fig. 1 flow chart of the Delphi method

The effectiveness evaluation indicators are divided into target layer, criterion layer and index layer combined with AHP method. The original data matrix of the index layer is denoted as $A=\left(a_{i j}\right)$ $\mathrm{n} \times \mathrm{m}$, among them, $\mathrm{n}$ represents that the number of comparison schemes is $\mathrm{n}, \mathrm{m}$ represents the number of the indicators in index layer are $\mathrm{m}, \mathrm{a}_{\mathrm{ij}}$ represents the value of the original index.

Step two normalized indicators

Because the physical meaning of each factor is different, the mathematical dimension is not always the same. There is a big gap between the magnitudes of the data and there is no comparability. Therefore, the original index values must be eliminated the dimension and transform to comparable data. For benefit index and cost index, the Eq. 4 and Eq. 5 are used to normalize the data separately to make each index value in the range of $[0,1]$.

$$
\begin{aligned}
& \mathrm{b}_{\mathrm{ij}}=\frac{\mathrm{a}_{\mathrm{ij}}}{\max _{\mathrm{i}=1}^{\mathrm{n}}\left(\mathrm{a}_{\mathrm{ij}}\right)} . \\
& \mathrm{b}_{\mathrm{ij}}=\frac{\min _{\mathrm{i}=1}^{\mathrm{n}}\left(\mathrm{a}_{\mathrm{ij}}\right)}{\mathrm{a}_{\mathrm{ij}}} .
\end{aligned}
$$

After the normalization of the data, the matrix is denoted as $B=\left(b_{i j}\right)_{n} \times m, b_{i j}$ is the normalized index value.

Step three combination weighting

The combination of AHP method and entropy method is the combination weighting method, the influence of the subjective and objective is considered which makes the result more reasonable and reliable. 
1) Use AHP to determine the subjective weights

(a) Determine the relative importance scale

The most direct reason for formulating the relative importance scale is to provide an evaluation standard to the experts. 1-9 scale method is used as a criterion that it is used to express the degree of importance of the index.

(b) Structure weight judgment matrix

According to the 1-9 scale method, the importance of indicators are given by experts, the judgment matrix of the weight is given and denoted as $\mathrm{C}=\left(\mathrm{c}_{\mathrm{ij}}\right)_{\mathrm{m}} \times \mathrm{m}$.

(c) Calculate weights of single layer index

The methods of calculating index weight have square root method and ANC, etc. The square root method is Eq. 6, it is used to calculate the weight of the index.

$$
w_{s i}=\frac{\left(\prod_{j=1}^{m} c_{i j}\right)^{\frac{1}{m}}}{\sum_{i=1}^{m}\left(\prod_{j=1}^{m} c_{i j}\right)^{\frac{1}{m}}} .
$$

The index weight vector is denoted as $\mathrm{w}_{\mathrm{sc}}=\left(\mathrm{w}_{\mathrm{s} 1}, \mathrm{w}_{\mathrm{s} 2}, \ldots, \mathrm{w}_{\mathrm{sm}}\right)$.

(d) Test of the consistency

When there are too many indicators, sometimes the expert's judgment appears contradictory situation, in order to avoid this kind of situation, the index through the Eq. 7 and Eq. 8 to carry out the consistency check.

$$
\begin{gathered}
C I=\frac{\lambda_{\max }-\mathrm{n}}{\mathrm{n}-1} . \\
C R=\frac{C I}{R I} .
\end{gathered}
$$

In the formula, $\lambda_{\max }$ is the biggest eigenvalue of the matrix $\mathrm{C}, \mathrm{n}$ is the rank of the matrix $\mathrm{C}$, and $\mathrm{RI}$ is the correction factor of the index system. When $\mathrm{CR}<0.1$, judgment matrix meet the consistency.

2) Use entropy method to determine the objective weight

The entropy method obtains the index weight according to the objective information provided by each index. The difference of the system index is measured by the entropy. If the entropy is bigger, the difference is smaller, the system uncertainty is bigger, and the weight should be smaller. On the contrary, the smaller the entropy, the greater the weight should be.

(a)The data in the matrix $B$ is calculated by Eq. 9 to obtain the matrix $D=\left(d_{i j}\right)_{n} \times m$.

$$
d_{i j}=\frac{b_{i j}}{\sum_{i=1}^{n} b_{i j}} \text {. }
$$

(b)The information entropy of the index bij is calculated by Eq. 10 .

$$
E_{\mathrm{oj}}=-\frac{1}{\ln n} \sum_{\mathrm{i}=1}^{\mathrm{n}} \mathrm{d}_{\mathrm{ij}} \operatorname{lnd}_{\mathrm{ij}} \text {. }
$$

(c)Calculate the weight of the index bij by Eq. 11.

$$
\mathrm{w}_{\mathrm{oj}}=\frac{1-E_{\mathrm{oj}}}{\sum_{\mathrm{k}=1}^{\mathrm{m}}\left(1-E_{\mathrm{ok}}\right)} \text {. }
$$

The objective weight of each index is recorded as $\mathrm{w}_{\mathrm{oc}}=\left(\mathrm{w}_{\mathrm{o} 1}, \mathrm{w}_{\mathrm{o} 2}, \ldots, \mathrm{w}_{\mathrm{om}}\right)$.

3) Combination weighting

$$
\mathrm{w}_{\mathrm{c}}=\frac{\mathrm{w}_{\mathrm{sc}} \mathrm{w}_{\mathrm{oc}}}{\sum_{\mathrm{c}=1}^{\mathrm{m}} \mathrm{w}_{\mathrm{sc}} \mathrm{w}_{\mathrm{oc}}} .
$$

Calculate the combination weight by Eq. $12, \mathrm{w}_{\mathrm{c}}$ is satisfied $0 \leq \mathrm{w}_{\mathrm{c}} \leq 1, \sum_{\mathrm{c}=1}^{\mathrm{m}} \mathrm{w}_{\mathrm{c}}=1$. 
Step four weighted processing of index layer index

The matrix $\mathrm{E}$ is obtained by weighting the indicators in the index layer

$E=\left[\begin{array}{cccc}\mathrm{e}_{11} & \mathrm{e}_{12} & \mathrm{~L} & \mathrm{e}_{1 \mathrm{~m}} \\ \mathrm{e}_{21} & \mathrm{e}_{22} & \mathrm{~L} & \mathrm{e}_{2 \mathrm{~m}} \\ \mathrm{M} & \mathrm{M} & \mathrm{L} & \mathrm{M} \\ \mathrm{e}_{\mathrm{n} 1} & \mathrm{e}_{\mathrm{n} 2} & \mathrm{~L} & \mathrm{e}_{\mathrm{nm}}\end{array}\right]=\left[\begin{array}{cccc}\mathrm{b}_{11} \cdot \mathrm{w}_{11} & \mathrm{~b}_{12} \cdot \mathrm{w}_{12} & \mathrm{~L} & \mathrm{~b}_{1 \mathrm{~m}} \cdot \mathrm{w}_{1 m} \\ \mathrm{~b}_{21} \cdot \mathrm{w}_{21} & \mathrm{~b}_{22} \cdot \mathrm{w}_{22} & \mathrm{~L} & \mathrm{~b}_{2 \mathrm{~m}} \cdot \mathrm{w}_{2 m} \\ \mathrm{M} & \mathrm{M} & \mathrm{L} & \mathrm{M} \\ \mathrm{b}_{\mathrm{n} 1} \cdot \mathrm{w}_{n 1} & \mathrm{~b}_{\mathrm{n} 2} \cdot \mathrm{w}_{n 2} & \mathrm{~L} & \mathrm{~b}_{\mathrm{nm}} \cdot \mathrm{w}_{n m}\end{array}\right]$

$\mathrm{e}_{\mathrm{ij}}=\mathrm{b}_{\mathrm{ij}} \times \mathrm{w}_{\mathrm{ij}}$ represents that the index value $\mathrm{b}_{\mathrm{ij}}$ is weighted. From the bottom of the index $\mathrm{c}$ to index $\mathrm{d}$ are the subordinate indicators of the index $i$ in criterion layer, $x_{n i}=\left(e_{n c}, e_{n c+1}, \ldots, e_{n d}\right), x_{n i}(1 \leq i \leq f)$ represents a collection of underlying indicators e in the scheme $n$.

Step five determine the reference sequence of the index layer

Reference scheme is an ideal scheme which denoted as $Y=\left[\left(\mathrm{y}_{11}, \mathrm{y}_{12}, \mathrm{~L} \mathrm{y}_{1 \mathrm{a}}\right)\left(\mathrm{y}_{21}, \mathrm{y}_{22}, \mathrm{~L} \mathrm{y}_{2 \mathrm{~b}}\right) \mathrm{L}\left(\mathrm{y}_{\mathrm{f} 1}, \mathrm{y}_{\mathrm{f} 2}, \mathrm{~L} \mathrm{y}_{\mathrm{fc}}\right)\right]=\left[\begin{array}{llll}Y_{1} & Y_{2} & \mathrm{~L} & Y_{\mathrm{f}}\end{array}\right], \mathrm{y}_{\mathrm{fc}}$ represents the ideal value of the index c, which is subordinate to the criterion layer index $\mathrm{f}, \mathrm{Y}_{\mathrm{f}}$ represents a set of indicators that are subordinate to the criteria layer index $\mathrm{f}$.

Step six calculate relational coefficient

Calculate the relational coefficient of each corresponding vector $X n i$ and $Y_{i}(1 \leq i \leq f)$ according to the formula (2), (3). The relational coefficient matrix is denoted as $R=(r)_{n} \times_{f}, r_{n f}$ represents the relational coefficient between the vector xnf in the comparison scheme $\mathrm{n}$ and the vector Yf in the reference scheme.

Step seven calculate the correlation degree and compositor

$$
E(A \mathrm{n})=\sum_{\mathrm{i}=1}^{\mathrm{f}} \mathrm{w}_{\mathrm{i}} \mathrm{r}_{\mathrm{ni}} \text {. }
$$

The relational degree of the comparison scheme is obtained according to the Eq. 13, and compositor according to the value of the relational degree. When the reference scheme is the optimal scheme, the greater the relational degree of the scheme is, the better the scheme is.

\section{Case analysis}

This paper analyzes the data based on references [12, 13], we selected two groups of track L1 and L2 that have representative significance from the results of the flight path planning to carry out the effectiveness evaluation. L1 represents the $3 \mathrm{UAVs}$ in the formation of the UAV is not at the same time to reach the goal for the collaborative planning of the track; L2 represents the UAVs arrive the goal at the same time. Comparison schemes are two so $n=2$, the index number of criterion layer is four so $f=4$. The index number of index layer is 12 so $\mathrm{m}=12$.

(1) Obtain the original data matrix

The indicators of this paper are benefit type, so the higher the value of the indicators is, the better the character of the indicators is. According to the relation of the criterion layer and the index layer, the original data matrix of the index layer is denoted as:

$\left[\begin{array}{lllllllllll}(6.8 & 4.8 & 7.4) & (6.2 & 5.2 & 7.4)(6.4 & 5.8) & (6.8 & 6.8 & 5.2 & 6.2) \\ (6.6 & 5.0 & 7.4) & (6.6 & 6.2 & 7.2)(6.6 & 6.0) & (7.0 & 6.8 & 5.4 & 6.4\end{array}\right]$

(2) normalize each element in the original data matrix according to the Eq. 4.

$\left.\left[\begin{array}{lll}1.0 & \frac{4.8}{5.0} & 1.0 \\ \frac{6.6}{6.8} & 1.0 & 1.0\end{array}\right)\left\{\begin{array}{ccc}\frac{6.2}{6.6} & \frac{5.2}{6.2} & 1.0 \\ (1.0 & 1.0 & \frac{7.2}{7.4}\end{array}\right)\left(\begin{array}{cc}\frac{6.4}{6.6} & \frac{5.8}{6.0} \\ (1.0 & 1.0\end{array}\right)\left(\begin{array}{cccc}\frac{6.8}{7.0} & 1.0 & \frac{5.2}{5.4} & \frac{6.2}{6.4} \\ (1.0 & 1.0 & 1.0 & 1.0\end{array}\right)\right]$

(3) Calculate the weights by the combination weighting method

$\mathrm{w} 1=(0.4899,0.2239,0.2862), \quad \mathrm{w} 2=(0.7315,0.1809,0.0877)$,

$\mathrm{w} 3=(0.3602,0.6398), \quad \mathrm{w} 4=(0.3266,0.1565,0.3671,0.1497)$,

$\mathrm{w}=(0.4153,0.3636,0.892,0.1318)$

(4) Calculate the relational coefficient matrix according to Eq. 2 and Eq. 3.

$\left[\begin{array}{l}R_{11} \\ R_{22}\end{array}\right]=\left[\begin{array}{llll}0.8481 & 0.4851 & 0.6761 & 0.7447 \\ 0.7763 & 0.9547 & 1.0000 & 1.0000\end{array}\right]$ 
(5) Calculate relational degree

Respectively, the relational coefficient R11 and R22 are weighted to calculate the relational degree according to Eq. 13.

$\mathrm{E}(\mathrm{L} 1)=0.687047512637669, \quad \mathrm{E}(\mathrm{L} 2)=0.890537237276898$

(6) Compositor according to the value of the relational degree

The scheme L1 is better than the scheme L2 due to E (L2) >E (L1). It is consistent with the result of reference [12]. The results of the three different methods are compared as shown in table 1. It shows that the improved method is reasonable and feasible.

Table 1: Comparison of the results obtained from three methods

\begin{tabular}{llll}
\hline & Method in the reference [12] & Traditional grey relational degree & this paper \\
\hline L1 & 0.76024 & 0.7913 & 0.6870 \\
L2 & 0.8521 & 0.9149 & 0.8905 \\
\hline
\end{tabular}

\section{Conclusions}

The improved method overcomes the shortcoming of the traditional grey relational degree method. (1) Even if the number of schemes is changed, the relational coefficient is not affected by the minimum absolute difference and the maximum absolute difference. (2) The compositor result of effectiveness evaluation is related to the Euclidean distance, which is not affected by the distinguishing coefficient of the subjective resolution. The result of the effectiveness evaluation is more consistent with the objective reality. (3) Using the combination weighting method is not only considering the experience knowledge of experts, but also increasing the objective information, which can improve the credibility of evaluation results. The improved method can be used to evaluate the effectiveness of complex systems and to solve the problem of multiple attribute decision making.

\section{References}

[1] Zhang Jie, Tang Hong, Su Kai, in: Research on the methods of effectiveness evaluation, edited by Beijing, National Defense Industry Press, (2009) in press.

[2] Hong Xiaozhi, Feng Helin. Improvement of grey relational degree quantization model. Statistics and Decision. Vol.9 (2014), p. 80 -83

[3] Wang Hao, Ji Yongqing, et al. Research on Comprehensive Optimization Based on Grey Association for Evaluating the Operational Effectiveness of Weapon System. Fire Control and Command Control.Vol.11 (2007),p.85 - 87

[4] Wu Kui, Wang Haibin. An Improved Analytic Network Process Effectiveness Evaluation Method Based on Grey Relational Analysis. MISSILE AND SPACE VEHCILE.Vol.5 (2013), p.66 - 69

[5] Chen Qin, Zhao Yu-hui, Du Jun. Application of the Improved Grey Correlation Analysis on Evaluating Radar Low Proability of Interception Performance. Fire Control Radar Technology. Vol.41 (2012), p.13 - 16

[6] Ma Qian. Performance evaluation method of data link network based on grey relational analysis. Technology Innovation and Application.Vol.24 (2015), p. 30 - 31

[7] Khanna R, Kumar A, Garg M P, et al. Multiple performance characteristics optimization for Al 7075 on electric discharge drilling by Taguchi grey relational theory. Journal of Industrial Engineering International, 2015.

[8] Tian min, Liu Sifeng et al. Review of the research on grey relational degree algorithm model. Statistics and Decision .Vol. 1 (2008), p.24- 27 
[9]FAN Kai, WU Hao-ying.A new method on identification coefficient of relational grade for gray system.Journal of Wuhan University of Technology. Vol.7 (2002), p.87 - 89

[10] Liu Weifeng, He Xia. A new grey relational degree model. Statistics and Decision.2011.Vol.14 (2011), p.160 - 161

[11] Song Dongmei, Liu Chunxiao et al. Multiple objective and attribute decision making based on the subjective and objective weighting. Journal of Shandong University.Vol.4 (2015), p.1 - 9

[12] Wu Jing. Research on Trajectory Planning and Effectiveness Evaluation for Multi-UAV Cooperative. Nanchang: Nanchang Hangkong University(2012)

[13] Huang Guo-qing, SuLin. Analysis of Effectiveness Evaluation Based on Improved Gray Synthesize Relational Degree .Command Control \& Simulation.Vol.3 (2015), p.90 - 93 